ARTICLE

\title{
Unveiling hydrocerussite as an electrochemically stable active phase for efficient carbon dioxide electroreduction to formate
}

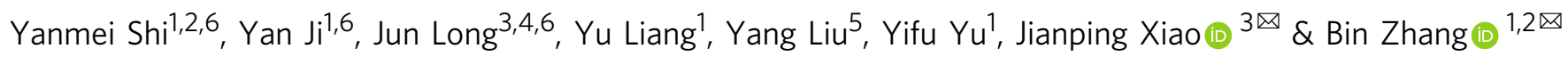

For most metal-containing $\mathrm{CO}_{2}$ reduction reaction $\left(\mathrm{CO}_{2} \mathrm{RR}\right)$ electrocatalysts, the unavoidable self-reduction to zero-valence metal will promote hydrogen evolution, hence lowering the $\mathrm{CO}_{2} \mathrm{RR}$ selectivity. Thus it is challenging to design a stable phase with resistance to electrochemical self-reduction as well as high $\mathrm{CO}_{2} \mathrm{RR}$ activity. Herein, we report a scenario to develop hydrocerussite as a stable and active electrocatalyst via in situ conversion of a complex precursor, tannin-lead(II) (TA-Pb) complex. A comprehensive characterization reveals the in situ transformation of $\mathrm{TA}-\mathrm{Pb}$ to cerussite $\left(\mathrm{PbCO}_{3}\right)$, and sequentially to hydrocerussite $\left(\mathrm{Pb}_{3}\left(\mathrm{CO}_{3}\right)_{2}(\mathrm{OH})_{2}\right)$, which finally serves as a stable and active phase under $\mathrm{CO}_{2} \mathrm{RR}$ condition. Both experiments and theoretical calculations confirm the high activity and selectivity over hydrocerussite. This work not only offers a new approach of enhancing the selectivity in $\mathrm{CO}_{2} \mathrm{RR}$ by suppressing the self-reduction of electrode materials, but also provides a strategy for studying the reaction mechanism and active phases of electrocatalysts.

\footnotetext{
${ }^{1}$ Institute of Molecular Plus, Department of Chemistry, School of Science, Tianjin University, Tianjin 300072, China. ${ }^{2}$ Tianjin Key Laboratory of Molecular Optoelectronic Science, Collaborative Innovation Center of Chemical Science and Engineering, Tianjin 300072, China. ${ }^{3}$ State Key Laboratory of Catalysis, Dalian Institute of Chemical Physics, Chinese Academy of Sciences, University of Chinese Academy of Sciences, Dalian 116023 , China. ${ }^{4}$ School of Science, Westlake University, Hangzhou 310024, China. ${ }^{5}$ Analysis and Testing Center, Tianjin University, Tianjin 300072, China. ${ }^{6}$ These authors contributed equally: Yanmei Shi, Yan Ji, Jun Long. ${ }^{凶}$ email: xiao@dicp.ac.cn; bzhang@tju.edu.cn
} 
E lectrocatalysis has emerged as a promising technology for renewable energy conversion and storage ${ }^{1-4}$, where a key factor is the development of electrocatalysts with higher activity, better selectivity, longer stability, and lower cost ${ }^{5,6}$. While the activity and stability are the two ends of a seesaw, the high activity of electrocatalysts often cannot be sustained for a long time, mainly because of the undesirable reconstruction of electrode surfaces. With the development of in situ characterization techniques, researchers have observed the structural transformation of electrocatalysts during the electrolysis ${ }^{7}$. Many efforts have been devoted to exploring the real active species derived from the pre-catalysts. For instance, metal oxyhydroxides, derived from the oxidative transformation of metal chalcogenides and pnictides, are found to be the active species for the oxygen evolution reaction (OER), promoting the rapid developments of highly efficient electrocatalytic materials for $\mathrm{OER}^{8-10}$. Thus the exploration of the real active species is of great importance for the rational design and synthesis of advanced electrocatalysts with high intrinsic activity.

Electrochemical $\mathrm{CO}_{2}$ reduction reaction $\left(\mathrm{CO}_{2} \mathrm{RR}\right)$ can convert the greenhouse gas $\left(\mathrm{CO}_{2}\right)$ to various value-added chemicals ${ }^{11-16}$, while the competing hydrogen evolution reaction (HER) is usually more favorable on many metallic electrodes. Although many high-valence metal electrocatalysts are proved to be reduced to zero-valence metal at $\mathrm{CO}_{2} \mathrm{RR}$ condition, such as $\mathrm{BiOI}{ }^{17}, \mathrm{PbO}_{2}{ }^{18}, \mathrm{SnO}_{2}{ }^{19}, \mathrm{CuO}^{20}, \mathrm{In}_{2} \mathrm{O}_{3}{ }^{21}$, it was found the residual metastable metal oxides are tightly correlated with the high selectivity towards $\mathrm{CO}_{2} \mathrm{RR}^{22-24}$. However, with the self-reduction occurring, HER becomes more and more dominant, leading to a diminished $\mathrm{CO}_{2} \mathrm{RR}$ efficiency. Besides, many complex electrocatalysts also undergo unavoidable dissociation and self-reduction under cathodic working conditions. For example, a Ni(II) benzenedithiol complex was revealed to be completely transformed to $\mathrm{Ni}$ nanosheets under cathodic conditions ${ }^{25}$. A $\mathrm{Cu}(\mathrm{II})$ phthalocyanine complex undergoes reversible conversion to metallic $\mathrm{Cu}$ clusters, which acts as the active species in $\mathrm{CO}_{2} \mathrm{RR}^{26}$. The selfreduction of electrocatalysts and the desirable $\mathrm{CO}_{2} \mathrm{RR}$ are actually competitive processes. To achieve high selectivity, developing electrocatalysts with predominant $\mathrm{CO}_{2} \mathrm{RR}$ over self-reduction is highly desirable.

Herein, we report a scenario to make effective use of the electrochemical structure evolution of a complex pre-catalyst, tannin-lead(II) (denoted as TA-Pb), toward high formate selectivity in $\mathrm{CO}_{2} \mathrm{RR}$. The $\mathrm{TA}-\mathrm{Pb}$ pre-catalyst performs a formate Faradaic efficiency (FE) of up to $96.4 \pm 0.9 \%$. Through a set of comprehensive characterizations, it is identified that $\mathrm{TA}-\mathrm{Pb}$ is transformed to cerussite $\left(\mathrm{PbCO}_{3}\right.$, denoted as $\left.\mathrm{PCO}\right)$ at first, then sequentially to hydrocerussite $\left(\mathrm{Pb}_{3}\left(\mathrm{CO}_{3}\right)_{2}(\mathrm{OH})_{2}\right.$, denoted as $\mathrm{PCOH})$ at steady state, which essentially serves as the active phase for highly selective formate production. In addition, we also synthesize pure cerussite nanoparticles and hydrocerussite nanoplates to confirm the transformation mechanism and the key role of hydrocerussite in $\mathrm{CO}_{2} \mathrm{RR}$, respectively. Moreover, the density functional theory (DFT) calculations also reveal the high formate selectivity, which can be attributed to the appropriate binding strength with $\mathrm{HCOO}^{*}$ on hydrocerussite. All the results unveil hydrocerussite as a highly selective and stable phase for formate production in $\mathrm{CO}_{2} \mathrm{RR}$.

\section{Results}

Electrochemical performances and transformation of $\mathrm{TA}-\mathrm{Pb}$. The tannin-lead(II) (TA-Pb) complex film is prepared by simply mixing $\mathrm{Pb}(\mathrm{II})$ and tannin aqueous solution in the presence of carbon fiber paper (CP) as the substrate (Fig. 1a). By examining with a high-resolution transmission electron microscope
(HRTEM), the coordination of TA and $\mathrm{Pb}$ (II) forms a layer of amorphous film contacting closely to the substrate with the thickness of $\sim 20 \mathrm{~nm}$ for single-layer $\mathrm{TA}-\mathrm{Pb}$ with $\mathrm{CP}$ as the substrate (inset in Fig. 1a, Supplementary Fig. 1 and Supplementary Note 1). The extended X-ray absorption fine structure (EXAFS) exhibits clear coordination of $\mathrm{Pb}-\mathrm{O}$ and $\mathrm{Pb}-\mathrm{C}$ for $\mathrm{a}$ five-membered ring in a chelate ligand (Fig. $1 \mathrm{~b})^{27}$, suggesting the 6-coordinated $\mathrm{Pb}(\mathrm{II})$ ions as reported before ${ }^{28}$.

The electrochemical activity was tested in a standard threeelectrode system with $0.5 \mathrm{M} \mathrm{NaHCO} 3$ as the electrolyte (Supplementary Fig. 2). Before $\mathrm{CO}_{2} \mathrm{RR}$ tests, all the samples were pre-treated under $-0.92 \mathrm{~V}$ for $30 \mathrm{~min}$ to reach the steady state. Liquid products were detected by nuclear magnetic resonance (NMR), while the gaseous ones were detected by gas chromatography (GC). The products in $\mathrm{CO}_{2} \mathrm{RR}$ with single-layer $\mathrm{TA}-\mathrm{Pb}$ as pre-catalyst are formate, $\mathrm{CO}$, and $\mathrm{H}_{2}$, which is in accordance with other reported $\mathrm{Pb}$-based electrocatalysts ${ }^{29-31}$. And $-0.92 \mathrm{~V}$ vs. reversible hydrogen electrode (RHE) is the optimum potential to achieve the highest formate FE (Supplementary Fig. 3 and Supplementary Note 2). The formate FE can be further improved by increasing the layers of the $\mathrm{TA}-\mathrm{Pb}$, and the 3-layer $\mathrm{TA}-\mathrm{Pb}$ complex shows the highest formate $\mathrm{FE}$ of $96.4 \pm 0.9 \%$ at the optimum potential of $-0.92 \mathrm{~V}$ with a small amount of $\mathrm{H}_{2}$ and negligible $\mathrm{CO}$. This is almost the highest value among $\mathrm{Pb}$-based electrocatalysts (Supplementary Table 1). The formate FE remains above $90 \%$ at a wide potential range from -0.82 to $-1.12 \mathrm{~V}$ (Fig. 1c). The result of inductively coupled plasma-mass spectrometry (ICP-MS) exhibits an extremely low Pb loading of $\sim 25 \mu \mathrm{g} \mathrm{cm}^{-2}$ for 3-layer $\mathrm{TA}-\mathrm{Pb}$, thus leading to a high formate turnover frequency (TOF) of $0.055 \mathrm{~s}^{-1}$ at the optimum potential of $-0.92 \mathrm{~V}$. Compared with the $\mathrm{TA}-\mathrm{Pb}$ pre-catalyst, $\mathrm{Pb}$ foil displays much lower formate FEs of $<40 \%$ (Supplementary Fig. 4). It is also noticed that the $j$ - $t$ curves of the as-prepared 3-layer TA$\mathrm{Pb}$ can be divided into three stages, i.e., stage I (0-3 min) with current density sharply declining, stage II (3-30 min) with current density increasing mildly, and stage III (>30 min) with almost constant current density (inset in Fig. 1d). These stages indicate the structural evolution of $\mathrm{TA}-\mathrm{Pb}$, whose details will be discussed later. At a steady state, the derived active species performs excellent stability of both formate $\mathrm{FE}$ and current density for $10 \mathrm{~h}$ (Fig. 1d). Labeled ${ }^{13} \mathrm{CO}_{2}$ was used to verify the carbon source of produced formate in control experiments under the optimum potential. As shown in the ${ }^{1} \mathrm{H}$ NMR spectrum in Fig. 1e, the $\mathrm{H}^{12} \mathrm{COO}^{-}$shows the chemical shift only at $8.35 \mathrm{ppm}$. The appearance of two new peaks at 8.61 and $8.13 \mathrm{ppm}$ indicates the formation of $\mathrm{H}^{13} \mathrm{COO}^{-}$, reflecting that carbon in formate is from $\mathrm{CO}_{2}$ rather than the decomposition of the complex.

Based on the three stages in Fig. 1d inset, we have captured another two different states derived from $\mathrm{TA}-\mathrm{Pb}$ in the electrolysis (Fig. 2a). The X-ray diffraction (XRD) patterns show that the two intermediate phases are cerussite $\left(\mathrm{PbCO}_{3}\right)$ and hydrocerussite $\left(\mathrm{Pb}_{3}\left(\mathrm{CO}_{3}\right)_{2}(\mathrm{OH})_{2}\right)$, respectively (Fig. 2b). And the phase of hydrocerussite maintains after a long-term test (Supplementary Fig. 5). The TA-Pb derived $\mathrm{PbCO}_{3}$ and $\mathrm{Pb}_{3}(\mathrm{OH})_{2}\left(\mathrm{CO}_{3}\right)_{2}$ are denoted as t-PCO and t-PCOH hereafter. Their corresponding HRTEM images show the decreasing thickness and increasing crystallinity along with the cathodic electrolysis (Supplementary Fig. 6). The structures of these intermediates were further identified by quasi-in-situ X-ray fine structure (XAFS). The EXAFS spectra of $\mathrm{t}-\mathrm{PCO}$ and $\mathrm{t}-\mathrm{PCOH}$ match well with the references cerussite and hydrocerussite, respectively (Fig. 2c). The similar $\mathrm{Pb} L_{3}$-edge in the $\mathrm{X}$-ray absorption near edge structures (XANES) of different stages indicates that the valence state of $\mathrm{Pb}$ remains unchanged during the electrochemical $\mathrm{CO}_{2} \mathrm{RR}$ measurements (Fig. 2d). 
a

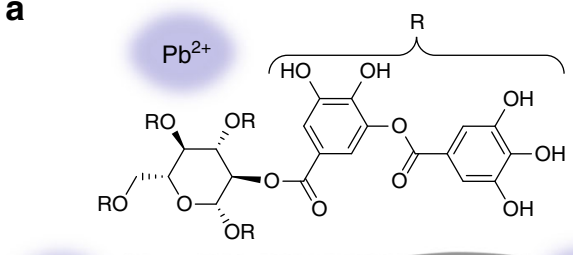

$\mathrm{Pb}^{2+}$<smiles>[TeH4-]</smiles>
(n)

Substrate

b

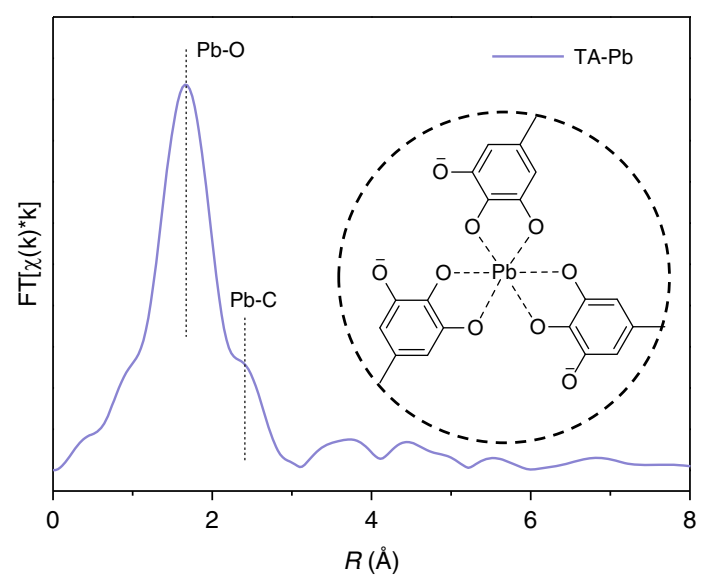

d

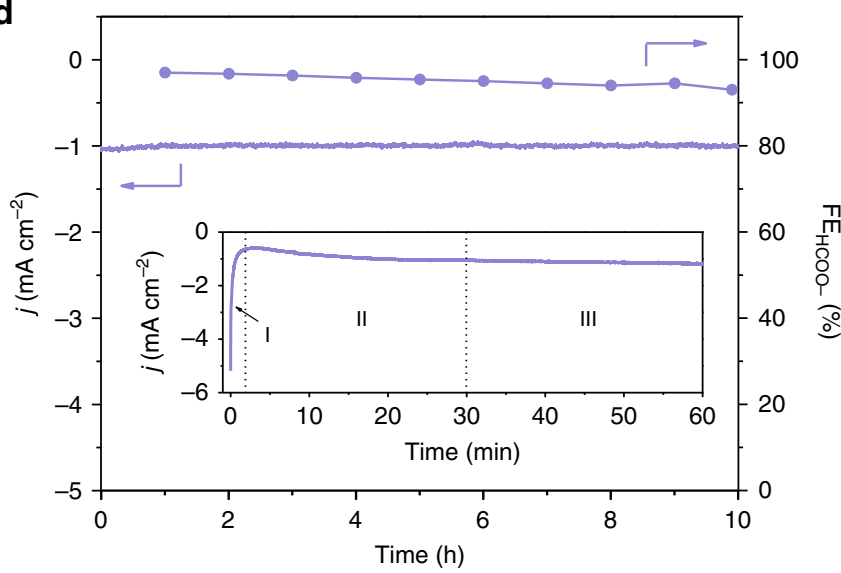

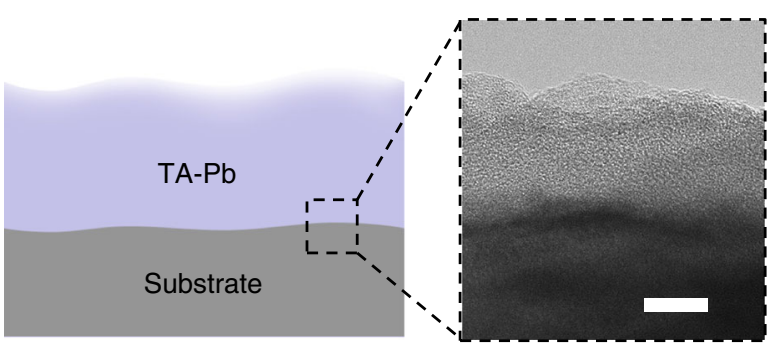

C

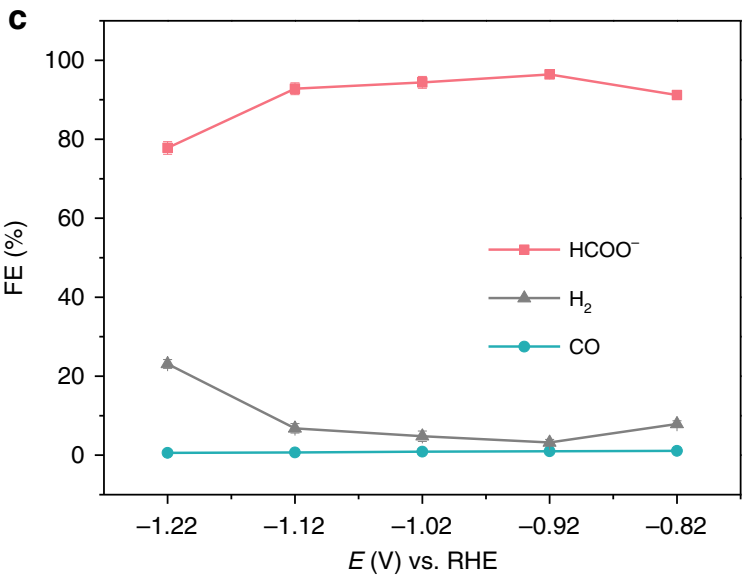

e

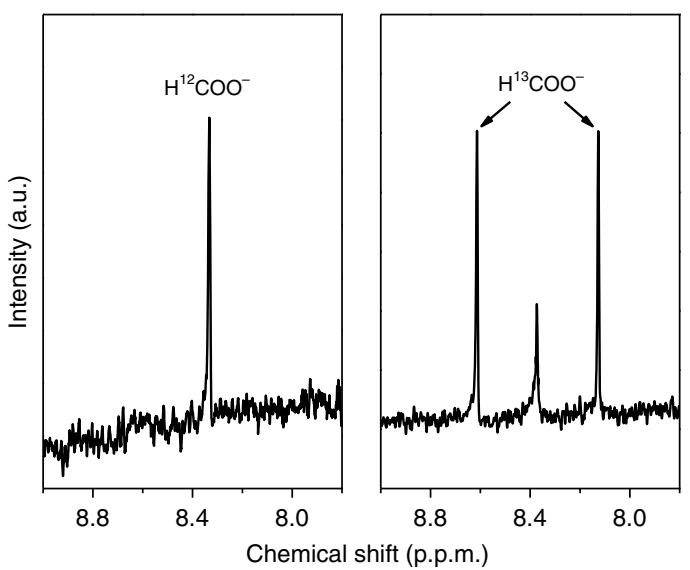

Fig. 1 Preparation, characterizations and electrochemical performances of TA-Pb. a A scheme illustrated for the TA-Pb preparation. The inset is the HRTEM image of single-layer TA-Pb. Scale bar, $10 \mathrm{~nm}$. b Pb $L_{3}$-edge EXAFS spectrum of TA-Pb. The inset is the proposed structure of TA-Pb. $\mathbf{c}$ FEs of 3-layer TA-Pb at steady state under different potentials. $\mathbf{d} j$-t curve and corresponding formate FE of 3-layer TA-Pb at steady state (stage III in the inset) under $-0.92 \mathrm{~V}$. The inset is the $j$-t curve of the as-prepared TA-Pb, which can be divided into three stages labeled as I, II, and III. e ${ }^{1} \mathrm{H}-\mathrm{NMR}$ spectra of formate by using ${ }^{12} \mathrm{CO}_{2}$ and ${ }^{13} \mathrm{CO}_{2}$ as feedstocks by using $0.5 \mathrm{M} \mathrm{Na}_{2} \mathrm{SO}_{4}$ as the electrolyte to eliminate the interference of $\mathrm{NaHCO}_{3}$. Error bars correspond to the standard error of the mean.

The X-ray photoelectron spectra (XPS) of TA-Pb clearly show the organic functional groups of tannin molecules in the $\mathrm{C} 1 \mathrm{~s}$ and O 1s spectra (Fig. 2e and Supplementary Fig. 7). However, these peaks of organic functional groups completely disappear in the t$\mathrm{PCO}$, suggesting the decomposition of the TA-Pb complex in stage I. The symmetric $\mathrm{O} 1 \mathrm{~s}$ peak of t-PCO at $532.7 \mathrm{eV}$ suggests the $\mathrm{O}$ element only exists in the form of $\mathrm{CO}_{3}{ }^{2-}{ }^{2}$. However, in $\mathrm{t}$ $\mathrm{PCOH}$, the appearance of a new peak represented $\mathrm{OH}^{-}$confirms the formation of hydrocerussite ${ }^{32}$. Similarly, the symmetric peak at $138.8 \mathrm{eV}$ is attributed to $\mathrm{PbCO}_{3}$ in the $\mathrm{Pb} 4 \mathrm{f} 7 / 2$ spectra of $\mathrm{t}$ PCO (Fig. 2f), while the peak at $138.3 \mathrm{eV}$ in t-PCOH represents the formation of $\mathrm{Pb}-\mathrm{OH}^{33}$. It should be pointed out that no $\mathrm{Pb}(0)$ is found throughout the whole process. And the cyclic voltammetry (CV) curve of $\mathrm{t}-\mathrm{PCOH}$ shows no redox peak in the tested range, firmly verifying the stability of hydrocerussite in $\mathrm{CO}_{2} \mathrm{RR}$ (Supplementary Fig. 8).

The transformation of the $\mathrm{TA}-\mathrm{Pb}$ complex was further investigated by Raman spectroscopy and Fourier transform infrared (FTIR) spectroscopy. The time-dependent in situ Raman spectra are shown in Fig. $2 \mathrm{~g}$. It is clearly shown that the fluorescent intensity from the ligand tannin ascends at first and then descends with the time prolonging (Supplementary Fig. 9,10), indicating the TA-Pb complex undergoes a part-towhole dissociation ${ }^{34}$. A small peak at $1065 \mathrm{~cm}^{-1}$ appears after electrolysis for 210 s, which is attributed to $\mathrm{C}-\mathrm{O}$ symmetric stretching vibration of $\mathrm{CO}_{3}{ }^{2-}{ }^{35}$, indicating the formation of $\mathrm{t}$ - 
a
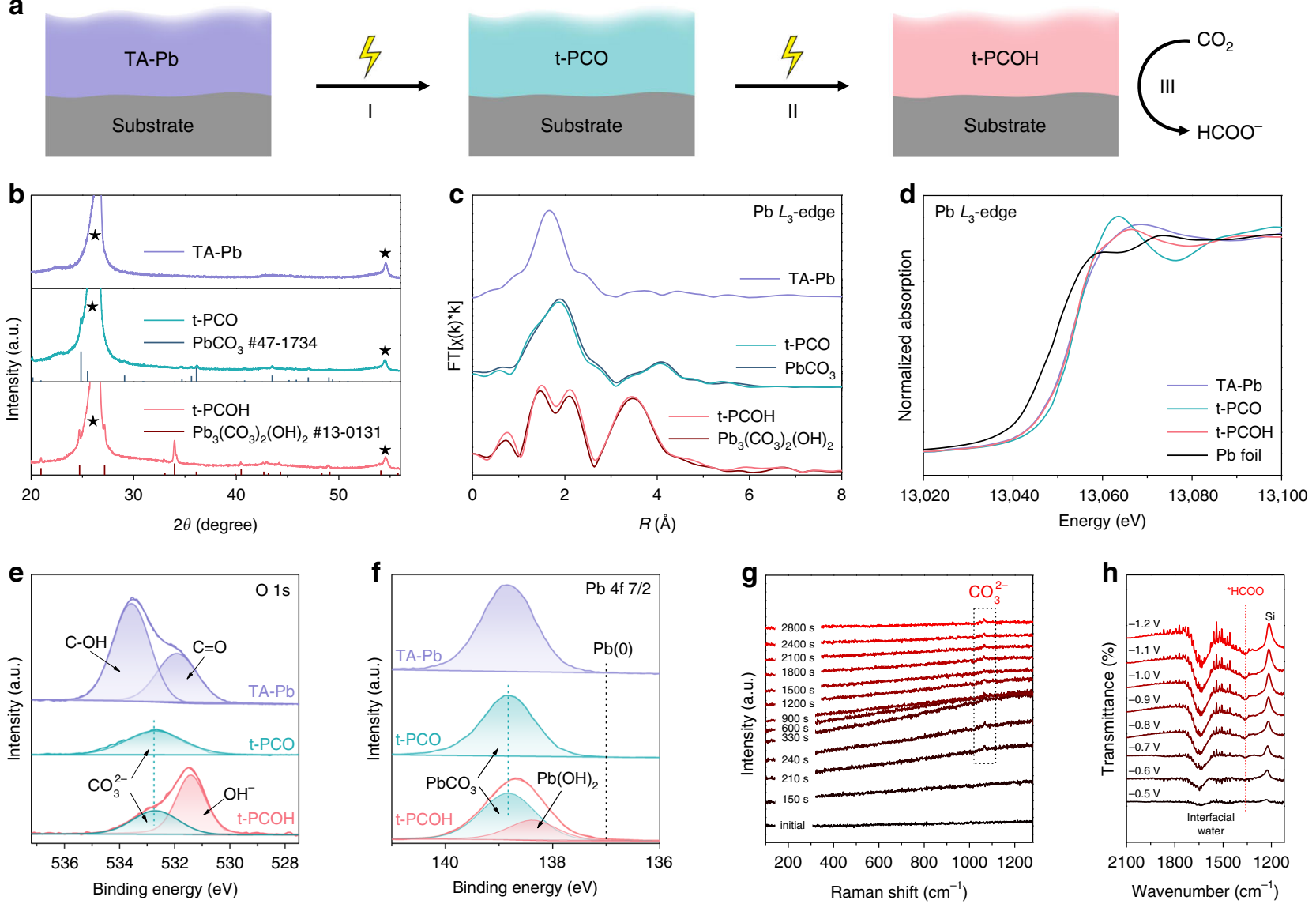

Fig. 2 Transformation of TA-Pb under cathodic potential. a lllustration of the transformation from TA-Pb to t-PCO and t-PCOH. $\mathbf{b} X R D$ patterns, $\mathbf{c}$ Quasiin-situ $\mathrm{Pb} \mathrm{L}_{3}$-edge EXAFS, $\mathbf{d}$ XANES spectra, e $\mathrm{O}$ 1s, and $\mathbf{f} \mathrm{Pb} 4 \mathrm{f} 7 / 2$ XPS spectra of TA-Pb, t-PCO and t-PCOH. The XRD peaks from the substrate are labelled by black stars. $\mathbf{g}$ Time-dependent in situ Raman spectra of TA-Pb under $\mathrm{CO}_{2}$ bubbling. $\mathbf{h}$ Potential-dependent in situ ATR-FTIR spectra of hydrocerussite with $\mathrm{CO}_{2}$ bubbling. The bands around 1640 and $1220 \mathrm{~cm}^{-1}$ are attributed to the adsorbed interfacial water and the vibration of Si-O from silicon as the reflection window, respectively 51 .

PCO. Because of the similar Raman spectroscopy shape of cerussite and hydrocerussite in this region ${ }^{36}$, the formation of $\mathrm{t}-\mathrm{PCOH}$ cannot be distinguished from Fig. $2 \mathrm{~g}$. It should be also noted that the peak of $\mathrm{CO}_{3}{ }^{2-}$ appears as early as the ascending process of fluorescence, which means that the dissociation of TA$\mathrm{Pb}$ and the formation of $\mathrm{t}-\mathrm{PCO}$ are accompanying rather than separate and sequential. Moreover, in ex situ FTIR spectra, the disappearance of the complex peaks again confirms the dissociation of the complex (Supplementary Fig. 11). In situ attenuated total reflectance-Fourier transform infrared (ATR-FTIR) spectroscopy was employed to investigate the reaction path of hydrocerussite. As shown in Fig. $2 \mathrm{~h}$, with the applied potential decreasing, the intensity of bands at $\sim 1360 \mathrm{~cm}^{-1}$ gradually increases (Supplementary Fig. 12 and Supplementary Note 3), which can be associated with the vibration of $\mathrm{O}-\mathrm{C}-\mathrm{O}$ in the twooxygen bridge-bonded formate species $\left({ }^{*} \mathrm{HCOO}\right)^{37}$, confirming the ${ }^{*} \mathrm{HCOO}$ pathway of hydrocerussite (Supplementary Fig. 13). No obvious band associating with $\mathrm{CO}^{*}$ can be found in the region of $1900-2100 \mathrm{~cm}^{-1}$, indicating that the formation of CO on hydrocerussite is almost inhibited ${ }^{38}$, which is consistent with the above experimental FE results. All the above results confirm that the $\mathrm{TA}-\mathrm{Pb}$ complex electrochemically dissociates and transforms into cerussite and hydrocerussite sequentially, in which the valence state of $\mathrm{Pb}$ remains +2 during the whole electrolysis, suggesting hydrocerussite to be the active species for electrochemical $\mathrm{CO}_{2} \mathrm{RR}$ via the pathway of ${ }^{*} \mathrm{HCOO}$ as the intermediate.
Performances of as-prepared cerussite and hydrocerussite. To further investigate the transformation of cerussite to hydrocerussite, we prepared cerussite nanoparticles (denoted as c-PCO) and studied their behavior under the same conditions of $\mathrm{CO}_{2} \mathrm{RR}$. The TEM image of the as-prepared c-PCO shows the irregular nanoparticles (Fig. 3a and Supplementary Fig. 14a). After tested at $-0.92 \mathrm{~V}$ in the presence of $\mathrm{CO}_{2}$ for $30 \mathrm{~min}$, it is found that the c-PCO nanoparticles completely transform to monocrystalline hexagonal nanosheets (Fig. 3b and Supplementary Fig. 14b). The corresponding selected area electron diffraction (SAED) pattern shows the dominant exposed facet of (0001) (inset in Fig. 3b). XRD pattern of the hexagonal nanosheets matches well with hexagonal hydrocerussite without any impurity (Fig. 3c), and the nanosheets is named as c-PCOH. XPS and ex situ Raman spectra also confirm the phase change from cerussite to hydrocerussite (Supplementary Figs. 15, 16). By studying the transformation process, it is found that the c-PCO nanoparticles first convert to cerussite nanoprisms via an Ostwald ripening process ${ }^{39,40}$, then to hexagonal hydrocerussite nanosheets through the selective etching of $\mathrm{CO}_{2}$ and the insertion of $\mathrm{OH}^{-}$(see more details in Supplementary Figs. 17-20 and Supplementary Notes 4-7).

The hydrocerussite nanoplates (shorted as h-PCOH) were also fabricated to estimate their $\mathrm{CO}_{2} \mathrm{RR}$ performance. The SEM image of the as-prepared hydrocerussite nanoplates performs quasihexagonal nanoplates with the diameter of several microns (Fig. 3d). After the $\mathrm{CO}_{2} \mathrm{RR}$ measurements, all the results of SEM images (Supplementary Fig. 21), XRD patterns (Fig. 3e), XPS 

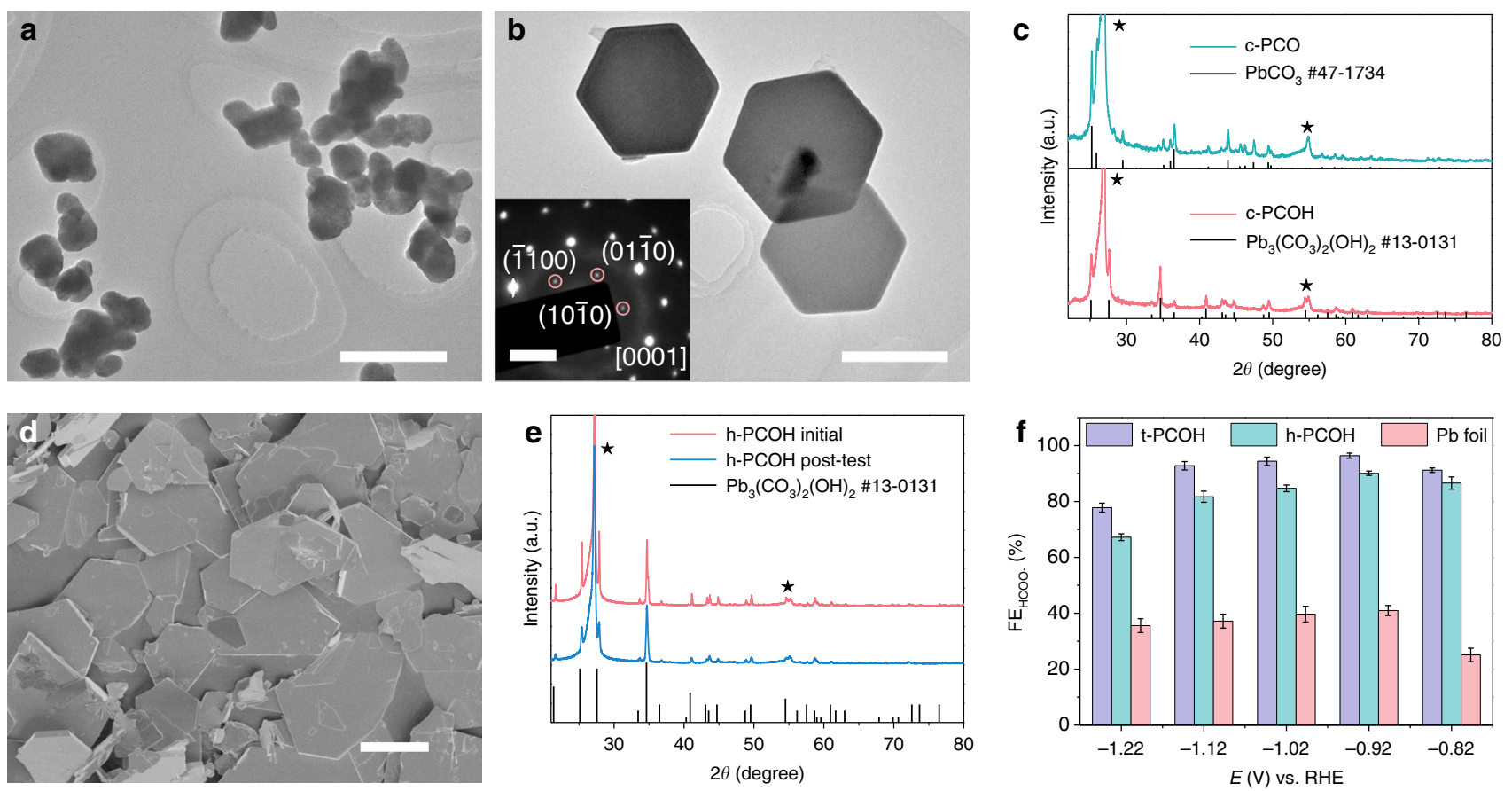

Fig. 3 Performances of c-PCO and h-PCOH under $\mathbf{C O}_{\mathbf{2}} \mathbf{R R}$ condition. a TEM image of c-PCO. Scale bar, $500 \mathrm{~nm}$. $\mathbf{b}$ TEM image of c-PCOH transformed from c-PCO. Scale bar, $500 \mathrm{~nm}$. The inset is the corresponding SAED pattern. Scale bar, $21 / \mathrm{nm}$. c XRD patterns of c-PCO and c-PCOH. The peaks from the substrate are labelled by black stars. $\mathbf{d}$ SEM image of the as-prepared h-PCOH. Scale bar, $10 \mu \mathrm{m}$. e XRD patterns of h-PCOH before and after the $\mathrm{CO}{ }_{2} \mathrm{RR}$ test for $5 \mathrm{~h}$. The peaks from the substrate are labelled by black stars. $\mathbf{f}$ Comparison of formate FEs of $\mathrm{t}-\mathrm{PCOH}, \mathrm{h}-\mathrm{PCOH}$, and $\mathrm{Pb}$ foil at different potentials. Error bars correspond to the standard error of the mean.

spectra (Supplementary Fig. 22) and ex situ Raman spectra (Supplementary Fig. 23) indicate that the morphology, structure, and composition of the h-PCOH remain unchanged, confirming that hydrocerussite is stable and the active species for $\mathrm{CO}_{2} \mathrm{RR}$. When compared the $\mathrm{CO}_{2} \mathrm{RR}$ performances of h-PCOH with $\mathrm{t}$ $\mathrm{PCOH}$, it is found that h-PCOH generates the similar products of dominant formate, a small amount of $\mathrm{H}_{2}$, and trace $\mathrm{CO}$ (Supplementary Fig. 24a). Specifically, h-PCOH performs the formate $\mathrm{FE}$ of $90.1 \pm 0.8 \%$ at $-0.92 \mathrm{~V}$ with the stability of over $10 \mathrm{~h}$ (Fig. 3f and S24b). The slightly lower FE of h-PCOH may originate from the poor coverage of the relatively large h-PCOH nanoplates (Supplementary Fig. 21), leaving part of the carbonaceous substrate exposed to give off much $\mathrm{H}_{2}$. The result, in turn, confirms the high coverage of in situ formed $\mathrm{t}-\mathrm{PCOH}$. Moreover, limited by the high mass loading of h-PCOH $(4.01 \mathrm{mg}$ $\mathrm{cm}^{-2}$ for $\mathrm{Pb}$ ), its TOF is calculated to be only $6.8 \times 10^{-4} \mathrm{~s}^{-1}$, which is 80 times lower than that of $\mathrm{t}-\mathrm{PCOH}$, further indicating a high catalytic efficiency of the complex-derived hydrocerussite.

DFT calculations. To understand the chemical origin of high formate selectivity in $\mathrm{CO}_{2} \mathrm{RR}$ over hydrocerussite, DFT calculations were performed. The hydrocerussite models are structured, and the optimized lattice parameters of $5.28 \times 5.30 \times 23.68 \AA$ are in good agreement with the experiments (Supplementary Fig. 25a $)^{41}$. As observed above, hydrocerussite prefers to expose the (0001) surface. In this way, there are three possible terminations of hydrocerussite (0001), denoted with Layer A, B, and C, as shown in Supplementary Fig. 25b. The B-termination is thermodynamically most stable with the surface energies $\left(E_{\mathrm{s}}\right)$ of $-0.24 \mathrm{eV} \mathrm{nm}^{-2}$ relative to $\mathrm{A}\left(E_{\mathrm{s}}=-0.04 \mathrm{eV} \mathrm{nm}^{-2}\right)$ and $\mathrm{C}\left(E_{\mathrm{s}}=\right.$ $\left.2.64 \mathrm{eV} \mathrm{nm}^{-2}\right)$. Besides, since hydrocerussite is in situ produced from the complex pre-catalyst, two kinds of vacancies $\left(\mathrm{CO}_{3}{ }^{2-}\right.$ or $\mathrm{OH}^{-}$removal) are considered herein. As a consequence, six possible active sites on hydrocerussite are examined to compared with the reference metallic $\mathrm{Pb}(111)$, including perfect $\mathrm{A}, \mathrm{B}$, and $\mathrm{C}$ terminations, denoted as A-p, B-p, and C-p, and defected A, B, and $\mathrm{C}$ ones, denoted as A-d, B-d, and C-d (Supplementary Fig. 25b). Then we calculated the adsorption energies of all the possible intermediates in $\mathrm{CO}_{2} \mathrm{RR}$ to producing $\mathrm{H}_{2}, \mathrm{CO}$, and formate, respectively. According to the result of in situ ATR-FTIR spectra, ${ }^{*} \mathrm{HCOO}$ adsorption energy is chosen as the descriptor to establish the correlation between different active sites and adsorbates, as shown in Supplementary Fig. 26.

The reaction free energies $(\Delta G)$ of all possible elementary steps are calculated and plotted versus the adsorption free energy of ${ }^{*} \mathrm{HCOO}\left[G_{\mathrm{ad}}(\mathrm{HCOO})\right]$ (Fig. $\left.4 \mathrm{a}\right)$, where the solid lines represent the $\Delta G$-determining steps of $\mathrm{HCOOH}, \mathrm{CO}$, and $\mathrm{H}_{2}$ production. The $\mathrm{HCOOH}$ production can follow two paths via either ${ }^{*} \mathrm{COOH}$ or ${ }^{*} \mathrm{HCOO}$, crossed at about $-1.3 \mathrm{eV}$. On A-p, B-p, and C-p, the $\Delta G$ for $\mathrm{HCOOH}$ production is unfavored (about $2.0 \mathrm{eV}$ ), which means at least $-2.0 \mathrm{~V}$ is needed to produce $\mathrm{HCOOH}$ on the perfect surfaces. On the contrary, the $\Delta G$-determining step on defected surfaces is smaller than $0.5 \mathrm{eV}$. On A-d and C-d, HER is more favorable than $\mathrm{HCOOH}$ and $\mathrm{CO}$. However, $\mathrm{HCOOH}$ is most preferred over $\mathrm{B}-\mathrm{d}$ via the ${ }^{*} \mathrm{HCOO}$ pathway, and the product selectivity preference obeys the order of $\mathrm{HCOOH}>\mathrm{H}_{2}>$ $\mathrm{CO}$, which is exactly consistent with our experiments. Besides, $\mathrm{B}-\mathrm{d}$ is the most stable termination and should be the dominant site of hydrocerussite. In comparison, the $\mathrm{HCOOH}$ activity and selectivity on $\mathrm{Pb}(111)$ are lower than the $\mathrm{B}-\mathrm{d}$ of hydrocerussite, in agreement with the low $\mathrm{HCOOH} \mathrm{FE}$ of $\mathrm{Pb}$ foil about $40 \%$ (Supplementary Fig. 4b). The explicit reaction free energy diagrams under $0 \mathrm{~V}$ vs. RHE on $\mathrm{B}$ - $\mathrm{d}$ of hydrocerussite and $\mathrm{Pb}$ (111) are displayed in Supplementary Fig. 27. On B-d, HCOOH is more favorable than $\mathrm{H}_{2}$ and $\mathrm{CO}$ in thermodynamics due to the stronger adsorption of ${ }^{*} \mathrm{HCOO}$ than ${ }^{*} \mathrm{H}$ and ${ }^{*} \mathrm{COOH}$ by 0.61 and $1.24 \mathrm{eV}$, respectively. $\mathrm{On} \mathrm{Pb}(111)$, although ${ }^{*} \mathrm{HCOO}$ is also more preferred than $* \mathrm{H}$, their small energy difference of only $0.17 \mathrm{eV}$ together with the higher concentration of proton than 

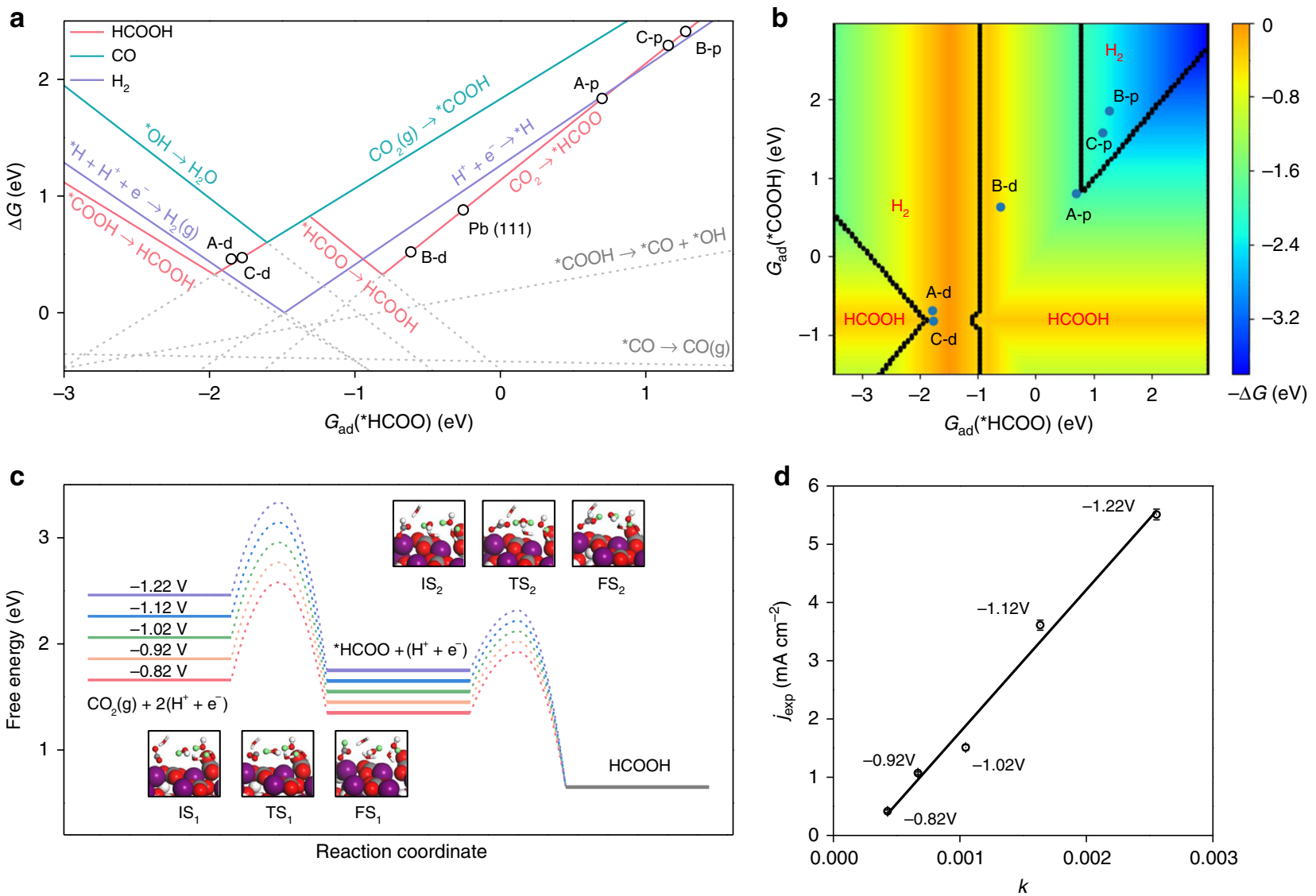

Fig. 4 Theoretically simulated the activity and selectivity of hydrocerussite. a Reaction free energies of involved elementary reactions plot versus $\mathrm{G}_{\mathrm{ad}}\left({ }^{\star} \mathrm{HCOO}\right)$. b Two-dimensional map of activity and selectivity for $\mathrm{CO}_{2} \mathrm{RR}$. Different regions represent different products, and colors represent the negative $\Delta G$ of GDS measured as the label on the right side. c Free energy diagrams of $\mathrm{CO}_{2} \mathrm{RR}$ into $\mathrm{HCOOH}$ under different experimental potentials; insets are structures of initial (IS), transition (TS) and final (FS) state of $\mathrm{CO}_{2}$ protonation (1) and $\mathrm{HCOOH}$ formation (2); purple, red, gray, and white atoms are $\mathrm{Pb}$, $\mathrm{O}, \mathrm{C}$, and $\mathrm{H}$, respectively; green atoms represent $\mathrm{H}$ that participate in the reaction. $\mathbf{d}$ Experimental partial current density of formate (jexp) versus theoretical charge transfer rate $k\left(10^{-17} \mathrm{C} \cdot \mathrm{s}^{-1} \cdot\right.$ site $\left.^{-1}\right)$. Error bars correspond to the standard error of the mean.

$\mathrm{CO}_{2}$ in an electrolyte, can actually reverse the preference of $\mathrm{HCOOH}$ and $\mathrm{H}_{2}$. Figure $4 \mathrm{~b}$ is the two-dimensional map of activity and selectivity of the sites of hydrocerussite, where $G_{\mathrm{ad}}(* \mathrm{COOH})$ is introduced as another dimension and varying independently with $G_{\mathrm{ad}}\left({ }^{*} \mathrm{HCOO}\right)$. The map contains four regions, which represent different products. Only B-d shows an obvious $\mathrm{HCOOH}$ preference and activity, further confirming B-d as the active site.

To analyze the effect of applied potential on $\mathrm{CO}_{2} \mathrm{RR}$ into $\mathrm{HCOOH}$, the potential-dependent barriers and reaction energies under different experimental potentials are calculated (Fig. 4c). At $-0.82 \mathrm{~V}$ vs. $\mathrm{RHE}$, the elementary reactions $\mathrm{CO}_{2}(\mathrm{~g})+\left(\mathrm{H}^{+}+\mathrm{e}^{-}\right)$ $\rightarrow{ }^{*} \mathrm{HCOO}$ and ${ }^{*} \mathrm{HCOO}+\left(\mathrm{H}^{+}+\mathrm{e}^{-}\right) \rightarrow \mathrm{HCOOH}$ are both exothermic, with a barrier of 0.82 and $0.57 \mathrm{eV}$, respectively. In kinetics, $\mathrm{CO}_{2}$ protonation is still more difficult than the formation of $\mathrm{HCOOH}$ and can be considered as the rate-determining step (RDS). As the potential decreases, the activation energy of $\mathrm{CO}_{2}$ protonation becomes lower gradually, which will increase the reaction rate and $\mathrm{HCOOH}$ partial current density in the experiment according to the transition state theory. Therefore, we further perform a microkinetic simulation to calculate the charge transfer rate of a single active site $(k)$ at different applied potentials. Figure $4 \mathrm{~d}$ shows the experimental $\mathrm{HCOOH}$ partial current density $\left(j_{\text {exp }}\right)$ plotted versus our theoretical charge transfer rate. A nice linear correlation has been established, confirming our calculations and analysis above regarding the active site and reaction mechanism.
Stablity of hydrocerussite. In the whole electrolysis, we attribute the high formate FE and electrochemical stability of hydrocerussite to its dominant $\mathrm{CO}_{2} \mathrm{RR}$. In this sense, both the electrochemical reduction from hydrocerussite to metal $\mathrm{Pb}$ and the competing HER are suppressed. It can be evidenced by the comparison of linear scan voltammetry (LSV) curves in Ar and $\mathrm{CO}_{2}$ (Supplementary Fig. 28). All the redox peaks under $\mathrm{Ar}$ completely disappear in $\mathrm{CO}_{2}$, suggesting the inhibition of $\mathrm{Pb}$ reduction under $\mathrm{CO}_{2}$ bubbling. Another controlled experiment is to test the stability of h-PCOH at $-0.92 \mathrm{~V}$ under Ar for $5 \mathrm{~h}$. Different from the results under $\mathrm{CO}_{2}$, the $\mathrm{FE}$ of hydrogen dramatically rises to over $80 \%$, and the formate $\mathrm{FE}$ decreases to around 5\% (Fig. 5a and Supplementary Fig. 29). Besides, with the electrolysis time prolonging, the hydrogen $\mathrm{FE}$ becomes larger and larger, while the formate FE goes smaller. And no $\mathrm{CO}$ can be detected under this condition. It should be noted that the total FE of all the products is obviously smaller than $100 \%$, suggesting that parts of the provided electrons are used to reduce the hydrocerussite. This conjecture can be further confirmed by the XRD pattern of this sample after electrolysis for $5 \mathrm{~h}$. As shown in Fig. 5b, the appearance of XRD peaks from $\mathrm{PbO}$ and metal $\mathrm{Pb}$ clearly demonstrates the decomposition and reduction of hydrocerussite under this condition, which is in accordance with the Pourbaix diagram of lead in the presence of $\mathrm{CO}_{3}{ }^{2-42}$. In addition, when the reduced hydrocerussite is tested in $\mathrm{CO}_{2}$ again, obvious decay of formate $\mathrm{FE}(\sim 60 \%)$ can be found just as our expectation (Fig. $5 \mathrm{c}$ ). From the above results, it is sure that the 

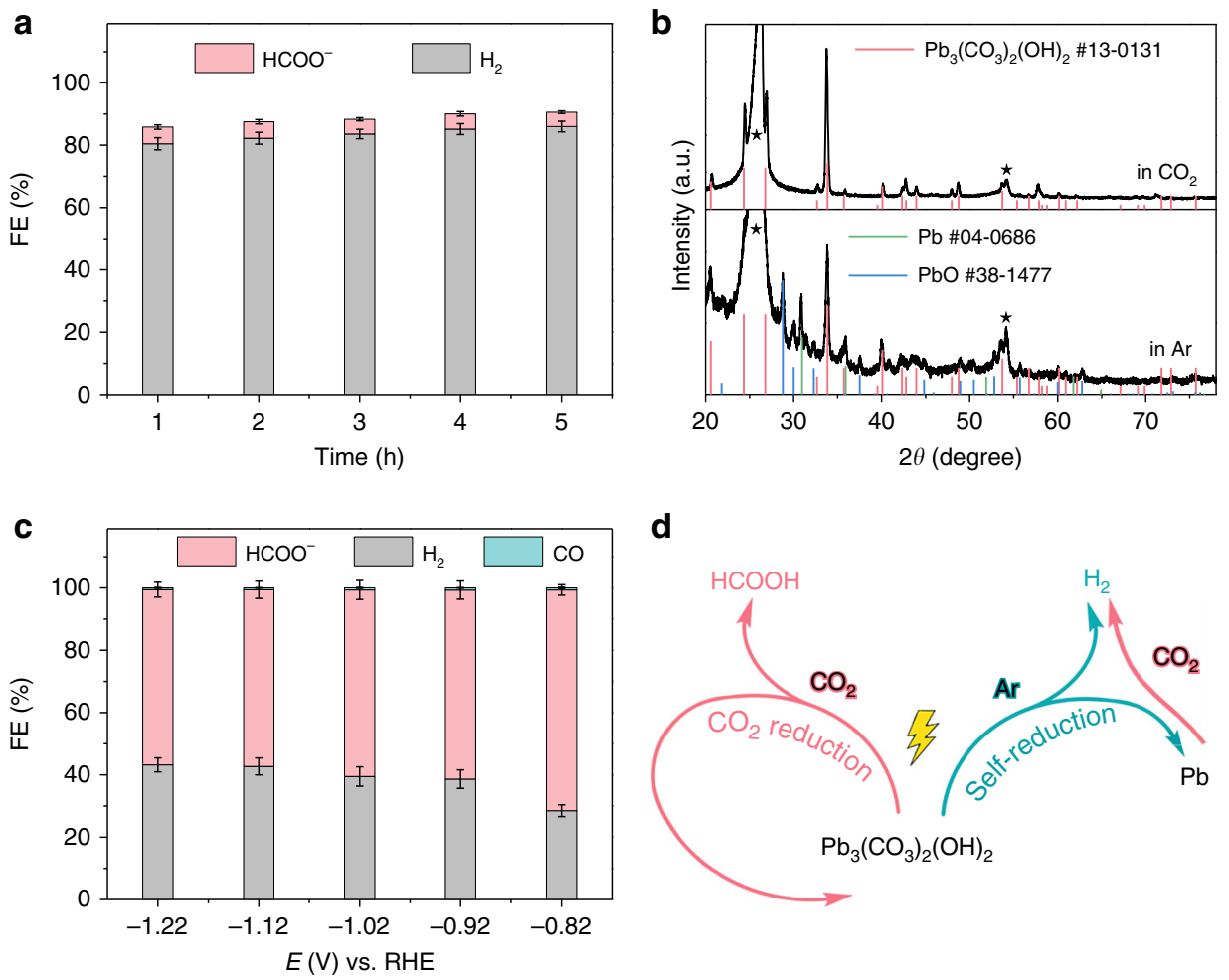

Fig. 5 Performances of hydrocerussite without $\mathbf{C O}_{\mathbf{2}}$ under cathodic potential in $\mathbf{N a H C O}_{\mathbf{3}}$. a FEs of $\mathrm{h}-\mathrm{PCOH}$ at $-0.92 \mathrm{~V}$ for $5 \mathrm{~h}$ in $\mathrm{Ar}$. $\mathbf{b} \mathrm{Comparison}$ of $\mathrm{XRD}$ patterns of $\mathrm{h}-\mathrm{PCOH}$ after electrolysis under $-0.92 \mathrm{~V}$ for $5 \mathrm{~h}$ in $\mathrm{CO}_{2}$ and in $\mathrm{Ar}$. The peaks from the substrate of $\mathrm{CP}$ are labelled by black stars. $\mathbf{c} \mathrm{FEs}$ of tested h- $\mathrm{PCOH}$ at different potentials in $\mathrm{CO}_{2}$. d Behaviors of hydrocerussite as the cathodic electrocatalyst. Error bars correspond to the standard error of the mean.

presence of $\mathrm{CO}_{2}$ is of great importance to maintain the stability of hydrocerussite under cathodic conditions. Without $\mathrm{CO}_{2}$, hydrocerussite is gradually decomposed and finally reduced to metal $\mathrm{Pb}$, accompanying with enhanced hydrogen evolution and weakened selectivity of formate production (Fig. 5d). In other words, the preference of $\mathrm{CO}_{2} \mathrm{RR}$ on hydrocerussite can effectively suppress the self-reduction of the electrocatalyst and the accompanying enhanced HER.

\section{Discussion}

In summary, we have revealed the dynamic change of $\mathrm{TA}-\mathrm{Pb}$ complex film as a model pre-catalyst under the conditions of $\mathrm{CO}_{2} \mathrm{RR}$, and finally unveiled hydrocerussite as the new active species for formate generation. The rapid transformation of $\mathrm{TA}-\mathrm{Pb}$ to cerussite ( $\mathrm{t}-\mathrm{PCO}$ ) and subsequent conversion to hydrocerussite ( $\mathrm{t}-\mathrm{PCOH}$ ) are revealed during the electrochemical $\mathrm{CO}_{2} \mathrm{RR}$ conditions. $\mathrm{t}-\mathrm{PCOH}$ is found to be the active species to produce formate with an optimum FE of $96.4 \pm 0.9 \%$. In addition, cerussite nanoparticles are prepared to verify the phase transformation to hydrocerussite. The hydrocerussite nanoplates are also directly fabricated, and perform similar high formate FE and long stability with $\mathrm{t}-\mathrm{PCOH}$, further confirming the key role of hydrocerussite. DFT calculations indicate that the hydrocerussite is highly active and selective for formate production. The excellent stability of hydrocerussite originates from its dominance of $\mathrm{CO}_{2} \mathrm{RR}$, thus the reduction of the electrocatalyst itself and consequent HER is blocked. This work not only opens a facile avenue to improve the $\mathrm{CO}_{2} \mathrm{RR}$ selectivity by suppressing the reduction of the electrocatalysts, but also establishes a guideline for fundamentally understanding the transformation process and active species of metal-complex catalytic materials for cathodic reactions.

\section{Methods}

Depositing TA-Pb complex on substrates. For a typical synthesis of a singlelayer $\mathrm{TA}-\mathrm{Pb}$ complex, a piece of the substrate was put in a clean and empty $20 \mathrm{~mL}$ vessel with the addition of $10 \mathrm{~mL} 10 \mathrm{mM} \mathrm{Pb}\left(\mathrm{NO}_{3}\right)_{2}$. After sufficient adsorption for $15 \mathrm{~min}, 10 \mathrm{~mL} 9 \mathrm{mg} \mathrm{mL}^{-1}$ tannic acid (TA) solution was quickly added. $2 \mathrm{M} \mathrm{NaOH}$ was then added to adjust $\mathrm{pH}$ to $\sim 7$. Then the vessel was gently shaken and stood at room temperature without disturbance for $6 \mathrm{~h}$. At last, the product was washed with water and dried naturally. To prepare multiple-layer $\mathrm{TA}-\mathrm{Pb}$, this procedure was repeated for suitable times. For instance, if this procedure was repeated for three times, the as-prepared products are named as the 3-layer TA-Pb. For environmental concerns, the $\mathrm{Pb}$-containing residual reaction solution was collected and stored in a dedicated container. $\mathrm{CP}$ was used as the substrate in electrochemical measurements. Before deposition, $\mathrm{CP}$ was cut into rectangular pieces with a size of $1 \times 3 \mathrm{~cm}^{2}$ and immersed in acetone and water for $15 \mathrm{~min}$ in sequence. Rutile $\mathrm{TiO}_{2}$ nanorod arrays supporting on F-doped tin oxide (FTO) glass were used as the substrate for TEM observation and ex situ FTIR spectroscopy. FTO glass was cut into a rectangular shape with a size of $1 \times 2.5 \mathrm{~cm}^{2}$, and sonicated in diluted $\mathrm{HCl}$, acetone, and water for $15 \mathrm{~min}$ in sequence. To prepare rutile $\mathrm{TiO}_{2}$ nanorod arrays, $15 \mathrm{~mL}$ water, $15 \mathrm{~mL}$ concentrated $\mathrm{HCl}$, and $0.5 \mathrm{~mL}$ tetrabutyl titanate were added to a Teflon-lined stainless-steel autoclave and stirred for $15 \mathrm{~min}$. A piece of clean FTO glass was put into the autoclave with the conductive side facing down. Then the autoclave was sealed and treated at $180^{\circ} \mathrm{C}$ for $1 \mathrm{~h}$. After the reactor cooled down naturally, the FTO with the white product was washed with water and alcohol, respectively, and dried naturally. Then the product was calcined in air at $500{ }^{\circ} \mathrm{C}$ for $2 \mathrm{~h}$ with the heating rate of $5^{\circ} \mathrm{C} \mathrm{min}-1$ to finally obtain the rutile $\mathrm{TiO}_{2}$ nanorod arrays.

Synthesis of c-PCO nanoparticles. c-PCO nanoparticles were prepared by a simple precipitation method. Briefly, $5 \mathrm{~mL} 1.2 \mathrm{M} \mathrm{Na}_{2} \mathrm{CO}_{3}$ and $5 \mathrm{~mL} 1.2 \mathrm{M} \mathrm{Pb}$ $(\mathrm{OAc})_{2} \cdot 3 \mathrm{H}_{2} \mathrm{O}$ were mixed and stirred for $5 \mathrm{~min}$. Then $10 \mathrm{~mL}$ water was added and stirred for another $1 \mathrm{~h}$ at room temperature. The white product was collected by centrifugation and washed with water and ethanol several times, then dried in a vacuum oven for $6 \mathrm{~h}$.

Synthesis of h-PCOH nanoplates. $2.50 \mathrm{~g} \mathrm{~Pb}\left(\mathrm{NO}_{3}\right)_{2}, 2.25 \mathrm{~g}$ urea, $0.075 \mathrm{~g}$ polyethylene glycol with the molecular weight of 2000 (PEG-2000), and $200 \mathrm{~mL}$ water were added in a flask. The flask was vigorously stirred and refluxed at $105^{\circ} \mathrm{C}$ for $5 \mathrm{~h}$. The product was collected by centrifugation and washed with water and ethanol several times, then dried in a vacuum oven for $6 \mathrm{~h}$ 
Characterization. The transmission electron microscopy (TEM) images and highresolution TEM (HRTEM) images were carried out with a JEOL JEM-2100F microscope. The scanning electron microscopy (SEM) images were taken with a Hitachi S-4800 microscope. The X-ray absorption fine structure (XAFS) were performed at the 1W1B beamline of Beijing Synchrotron Radiation Facility (BSRF), And the XAFS spectra were analyzed with the ATHENA software package ${ }^{43}$. The $k$-weighting was set to 1 for the Fourier transforms. Fourier transforms of $\chi(k)$ were performed in the k-range of $2-8 \AA^{-1}$ with the Hanning window function. All the EXAFS spectra were without phase correction. The gaseous products of electrochemical $\mathrm{CO}_{2} \mathrm{RR}$ were detected by a GC (Shimadzu GC-2010). And the formate was measured by a $400 \mathrm{MHz}$ NMR spectrometer (Bruker AVANCE III HD). The determination of formate was based on the internal standard method by using $100 \mathrm{ppm}$ dimethylsulfoxide (DMSO) as the internal standard substance. The XRD patterns were recorded on a Bruker D8-Focus diffraction system with a $\mathrm{Cu} \mathrm{K \alpha}$ source $(\lambda=1.54056 \AA)$. The ICP-MS was collected on an Agilent 7700X instrument. The XPS were carried out with a Thermo ESCALAB 250XI spectrometer. All the peaks were calibrated with $\mathrm{C} 1 \mathrm{~s}$ spectrum at the binding energy of $284.8 \mathrm{eV}$. The Raman spectra were recorded on a Renishaw inVia reflex Raman microscope under an excitation of $532 \mathrm{~nm}$ laser with the power of $20 \mathrm{~mW}$. The ex situ FTIR were taken with a Bruker ALPHA-T FTIR spectrometer.

Electrochemical measurements. All the electrochemical measurements were taken with a CHI 650e electrochemical workstation (CH Instruments, Austin, TX). A typical three-electrode system was employed in a home-made H-type electrolytic cell. Generally, $0.5 \mathrm{M} \mathrm{NaHCO}_{3}$ was used as the electrolyte. Only with ${ }^{13} \mathrm{CO}_{2}$ as the feedstock, $0.5 \mathrm{M} \mathrm{Na}_{2} \mathrm{SO}_{4}$ was used as the electrolyte to eliminate the effect of carbonate species from $\mathrm{NaHCO}_{3}$. Before the measurements, $\mathrm{Ar}$ or $\mathrm{CO}_{2}$ was bubbled to the system for over $30 \mathrm{~min}$ to remove the dissolved oxygen and continuously bubbled throughout the measurements. TA-Pb supported on $\mathrm{CP}$ and $\mathrm{Pb}$ foil were used as a working electrode directly. For the powder samples like c- $\mathrm{PCO}$ and h-PCOH, $5 \mathrm{mg}$ sample was first dispersed in $1 \mathrm{~mL}$ ethanol with the addition of $20 \mu \mathrm{L} \%$ Nafion 117 solution. After sufficient sonification, all the $1 \mathrm{~mL}$ homogeneous ink solution was carefully dropped on a piece of $\mathrm{CP}$ with the exposed area of $1 \mathrm{~cm}^{2}$ by epoxy coating, making the mass loading to be $5 \mathrm{~m} \mathrm{~cm}^{-2}$. Saturated calomel electrode (SCE) and Pt sheet were used as the reference electrode and counter electrode, respectively. All the potentials mentioned in this work were against the RHE without additional description. The scan rate for all the voltammetry was $10 \mathrm{mV} \mathrm{s}^{-1}$. Before all $\mathrm{CO}_{2} \mathrm{RR}$ measurements, each sample was tested at $-0.92 \mathrm{~V}$ for $30 \mathrm{~min}$ to achieve the steady state. For potential-dependent FE measurements, the sample was maintained at the specific potential for another 30 min to accumulate enough products. For environmental concerns, we analyzed the $\mathrm{Pb}$ content in the electrolyte after tests by ICP-MS. The result showed that only $4.418 \mu \mathrm{g} \mathrm{L}^{-1} \mathrm{~Pb}$ was detected, which was obviously lower than the Chinese Standards for Drinking Water Quality (GB 5749-2006) of $0.01 \mathrm{mg} \mathrm{L}^{-1}$ for $\mathrm{Pb}$, indicating that the use of hydrocerussite as electrocatalyst for $\mathrm{CO}_{2} \mathrm{RR}$ was eco-friendly.

Calculation of TOF. The calculation of TOF is based on Eq. (1) as follows.

$$
\mathrm{TOF}=\frac{n_{\mathrm{f}}}{n_{\mathrm{c}} \times t},
$$

where $n_{\mathrm{f}}$ is the amount of the generated formate, $n_{c}$ is the amount of the active catalyst site, and $t$ is the duration time. In this work, we assume all the $\mathrm{Pb}$ sites are active for the reaction. The generated formate is calculated according to Eq. (2).

$$
n_{\mathrm{f}}=\frac{\mathrm{Q} \times \mathrm{FE}_{\mathrm{f}}}{2 \times F},
$$

where $Q$ is the integrated coulombs from the $I-t$ curve of $\mathrm{TA}-\mathrm{Pb}, \mathrm{FE}_{\mathrm{f}}$ is the $\mathrm{FE}$ of formate, and $F$ is the Faradaic constant.

Electrochemical in situ spectroscopy. In situ ATR-FTIR spectra were obtained on a Nicolet 6700 FTIR spectrometer with silicon as the prismatic window. A thin layer of gold film was chemically deposited on the surface of the silicon prismatic prior to each experiment. Then $20 \mu \mathrm{L}$ sample ink was carefully dropped on the surface of the gold film, together served as the working electrode. Pt sheet and $\mathrm{Ag} / \mathrm{AgCl}$ were used as the counter electrode and the reference electrode, respectively. $0.5 \mathrm{M} \mathrm{NaHCO}_{3}$ was employed as the electrolyte. $\mathrm{CO}_{2}$ or argon was bubbling to the electrolyte in advance and continuously bubbled throughout the experiment. The in situ Raman spectroscopy of the decomposition of $\mathrm{TA}-\mathrm{Pb}$ was carried out on the same Raman microscope mentioned before at $-1.22 \mathrm{~V}$ vs. RHE in $0.5 \mathrm{M} \mathrm{NaHCO}_{3}$ with $\mathrm{CO}_{2}$ bubbling. The electrolytic cell was homemade by Teflon with a piece of round quartz glass as the cover to protect the objective of the microscope. A piece of $\mathrm{TA}-\mathrm{Pb}$ supported on $\mathrm{CP}$ was inserted through the wall of the cell to keep the plane of the working electrode perpendicular to the incident laser. Pt wire as the counter electrode was rolled to a circle around the working electrode. SCE was used as a reference electrode. Quasi-insitu XAFS spectra were acquired by measuring the electrochemical performances of the sample just near the synchrotron radiation facility, then the tested sample was immediately delivered to the facility for XAFS measurements.

Computational details. DFT calculations were performed with the Vienna Ab initio Simulation Package ${ }^{44,45}$. The revised Perdew-Burke-Ernzerhof (rPBE) ${ }^{46}$ exchange- correlation functional was adopted as the level of generalized gradient approximation (GGA). The atomic valence orbitals were described by plane-wave basis sets with the kinetic cutoff energies of $400 \mathrm{eV}$. A Gaussian smearing with a width of $0.2 \mathrm{eV}$ was used. All the total energy calculations were converged at $0.05 \mathrm{eV} / \AA$. The hydrocerussite (0001) surface with a vacuum of $20 \AA$ was used to model experimental hydrocerussite samples. Six layers were contained in the slab, with the top three relaxed and the rest fixed. A $(4 \times 4) \mathrm{Pb}(111)$ slab with 4 layers was used to model $\mathrm{Pb}$ foil, where the top two were allowed to be relaxed. To calculate the protonation barriers, a layer of $\mathrm{H}_{2} \mathrm{O}$ with a density of $\sim 1 \mathrm{~g} \mathrm{~cm}^{-2}$ was introduced upon the surface of catalysts.

Reaction phase diagram. All the adsorption free energies of intermediates were first calculated, referenced to $\mathrm{CO}(\mathrm{g}), \mathrm{H}_{2}(\mathrm{~g})$, and $\mathrm{H}_{2} \mathrm{O}(\mathrm{g})$. All the adsorption free energies could be correlated with that of $* \mathrm{HCOO}$, in the format of $G_{\mathrm{ad}}\left({ }^{*} \mathrm{X}\right)=a \times G_{\mathrm{ad}}\left({ }^{*} \mathrm{H}-\right.$ $\mathrm{COO})+b$, where $G_{\mathrm{ad}}(* \mathrm{X})$ was the adsorption free energy of intermediate $\mathrm{X}$ and $G_{\mathrm{ad}}\left({ }^{\mathrm{HCOO}}\right)$ was that of $* \mathrm{HCOO}$, used as descriptor herein. Then, the reaction free energy $(\Delta G)$ of all involved elementary steps, such as ${ }^{*} \mathrm{COOH}+\left(\mathrm{H}^{+}+\mathrm{e}^{-}\right) \rightarrow$ $\mathrm{HCOOH}$, can be calculated by $\Delta G=G(\mathrm{HCOOH})-G\left(\mathrm{H}^{+}+\mathrm{e}^{-}\right)-G_{\text {ad }}\left({ }^{*} \mathrm{COOH}\right)$, where $G(\mathrm{HCOOH})$ was the chemical potential of formic acid and $G\left(\mathrm{H}^{+}+\mathrm{e}^{-}\right)$was referred to $1 / 2 \mathrm{H}_{2}$ under $U=0 \mathrm{~V}$ vs. $\mathrm{RHE}^{47}$, respectively, referenced to the same criterion with adsorption energies. Obviously, $G(\mathrm{HCOOH})$ and $G\left(\mathrm{H}^{+}+\mathrm{e}^{-}\right)$were constants, and $G_{\text {ad }}\left(\mathrm{COOH}^{*}\right)$ was linearly correlated with $G_{\text {ad }}\left({ }^{*} \mathrm{HCOO}\right)$. Therefore, the reaction free energy as a linear function of $G_{\mathrm{ad}}\left({ }^{*} \mathrm{HCOO}\right)$ could be obtained (Fig. 4a), which was defined as the reaction phase diagram in our previous report ${ }^{48}$. Besides, a two-dimensional map of activity and selectivity (Fig. 4b) could be obtained by making $G_{\text {ad }}\left({ }^{*} \mathrm{COOH}\right)$ vary independently with $G_{\mathrm{ad}}\left({ }^{*} \mathrm{HCOO}\right)$ and analytically calculating the corresponding reaction free energy at every pair of $G_{\mathrm{ad}}\left({ }^{*} \mathrm{COOH}\right)$ and $G_{\mathrm{ad}}\left({ }^{*} \mathrm{HCOO}\right)$, which can give a more accurate description on the activity and selectivity.

Potential-dependent barrier and reaction energy. The potential effect on thermodynamic reaction free energy was considered by changing the chemical potential of $\left(\mathrm{H}^{+}+\mathrm{e}^{-}\right)$by $-e U$, as suggested in the computational hydrogen electrode ${ }^{47}$ approximation. The potential-dependent kinetic barriers of electrochemical reaction $\left({ }^{*} \mathrm{~A}+\mathrm{H}^{+}+\mathrm{e}^{-} \rightarrow{ }^{*} \mathrm{AH}\right)$ were calculated by using an equivalent analogous non-electrochemical reaction $\left({ }^{*} \mathrm{~A}+{ }^{*} \mathrm{H} \rightarrow{ }^{*} \mathrm{AH}\right)$ combined with Marcus theory, an effective method developed by Janik et al. ${ }^{49,50}$.

Microkinetics simulations. The rate of $\mathrm{CO}_{2}$ protonation is considered as the total reaction rate since it is the RDS. The rate constant (a) was determined by:

$$
a=A \mathrm{e}^{\frac{-G_{a}}{k_{b}}}
$$

where $G_{\mathrm{a}}$ is the activation free energy; $k_{b}$ is the Boltzmann constant and $T$ is temperature. $A$ is the prefactor and calculated by:

$$
A=\frac{k_{b} T}{h} \frac{Q_{\mathrm{ts}}}{Q},
$$

where $h$ is the Planck constant; $Q_{\mathrm{ts}}$ and $Q$ refer the partition functions of the transition and initial states, respectively. $A$ was approximated to be $10^{13} \mathrm{~s}^{-1}$ for surface reactions in this work. The forward rate of $\mathrm{CO}_{2}$ protonation $\left[\mathrm{CO}_{2}(\mathrm{~g})+\right.$ $\left.\left(\mathrm{H}^{+}+\mathrm{e}^{-}\right)+{ }^{*} \rightarrow{ }^{*} \mathrm{HCOO}\right]$ was calculated by:

$$
\begin{gathered}
r=a c\left(\mathrm{CO}_{2}\right) c\left(\mathrm{H}^{+}\right) \theta^{*} \\
=A e^{\frac{-G_{a}}{k_{b} T}}\left[c\left(\mathrm{CO}_{2}\right) c\left(\mathrm{H}^{+}\right) \theta^{*},\right.
\end{gathered}
$$

where $c\left(\mathrm{CO}_{2}\right), c\left(\mathrm{H}^{+}\right)$and $\theta^{*}$ are the concentration of $\mathrm{CO}_{2}$ and proton in electrolyte and coverage of the free active site, respectively. The charge transfer rate on a single active site $(k)$ is:

$$
\begin{gathered}
k=r z F \\
=A e^{\frac{-G_{a}}{k_{b} T}}\left[c\left(\mathrm{CO}_{2}\right) c\left(\mathrm{H}^{+}\right) \theta^{*}\right] z F,
\end{gathered}
$$

where $z$ is the total number of electrons transferred in the overall reaction, $F=$ $1.6 \times 10^{-19}$

In principle, $c\left(\mathrm{CO}_{2}\right), c\left(\mathrm{H}^{+}\right)$and $\theta^{*}$ are constant at different potentials, hence the term $\left[c\left(\mathrm{CO}_{2}\right) c\left(\mathrm{H}^{+}\right) \theta^{*}\right]$ is assumed to be 1 in this study. By this approximation, the charge transfer rate $k$ under different potentials can be estimated.

\section{Data availability}

The source data underlying Figs. 1-5 are provided as a Source Data file. The data that support other plots within this paper are available from the corresponding author upon reasonable request.

Received: 19 January 2020; Accepted: 11 June 2020; Published online: 08 July 2020 


\section{References}

1. Seh, Z. W. et al. Combining theory and experiment in electrocatalysis: Insights into materials design. Science 355, eaad4998 (2017).

2. Wakerley, D. et al. Bio-inspired hydrophobicity promotes $\mathrm{CO}_{2}$ reduction on a Cu surface. Nat. Mater. 18, 1222-1227 (2019).

3. Long, C. et al. Electrochemical reduction of $\mathrm{CO}_{2}$ over heterogeneous catalysts in aqueous solution: Recent progress and perspectives. Small Methods 3, 1800369 (2018).

4. Lewis, N. S. \& Nocera, D. G. Powering the planet: Chemical challenges in solar energy utilization. Proc. Natl Acad. Sci. USA 103, 15729-15735 (2006).

5. Gao, S. et al. Partially oxidized atomic cobalt layers for carbon dioxide electroreduction to liquid fuel. Nature 529, 68 (2016).

6. Ross, M. B. et al. Designing materials for electrochemical carbon dioxide recycling. Nat. Catal. 2, 648-658 (2019).

7. Handoko, A. D., Wei, F., Jenndy, Yeo, B. S. \& Seh, Z. W. Understanding heterogeneous electrocatalytic carbon dioxide reduction through operando techniques. Nat. Catal. 1, 922-934 (2018).

8. Jin, S. Are metal chalcogenides, nitrides, and phosphides oxygen evolution catalysts or bifunctional catalysts? ACS Energy Lett. 2, 1937-1938 (2017).

9. He, Q. et al. Highly defective Fe-based oxyhydroxides from electrochemical reconstruction for efficient oxygen evolution catalysis. ACS Energy Lett. 3, 861-868 (2018).

10. Fan, K. et al. Direct observation of structural evolution of metal chalcogenide in electrocatalytic water oxidation. ACS Nano 12, 12369-12379 (2018).

11. Voiry, D., Shin, H. S., Loh, K. P. \& Chhowalla, M. Low-dimensional catalysts for hydrogen evolution and $\mathrm{CO}_{2}$ reduction. Nat. Rev. Chem. 2, 0105 (2018).

12. Gu, J., Hsu, C.-S., Bai, L., Chen, H. M. \& Hu, X. Atomically dispersed Fe $\mathrm{F}^{3+}$ sites catalyze efficient $\mathrm{CO}_{2}$ electroreduction to CO. Science 364, 1091-1094 (2019).

13. Wu, J., Sharifi, T., Gao, Y., Zhang, T. \& Ajayan, P. M. Emerging carbon-based heterogeneous catalysts for electrochemical reduction of carbon dioxide into value-added chemicals. Adv. Mater. 31, e1804257 (2019).

14. Liu, Y. \& McCrory, C. C. L. Modulating the mechanism of electrocatalytic $\mathrm{CO}_{2}$ reduction by cobalt phthalocyanine through polymer coordination and encapsulation. Nat. Commun. 10, 1683 (2019).

15. Jiang, $\mathrm{K}$. et al. Metal ion cycling of $\mathrm{Cu}$ foil for selective $\mathrm{C}-\mathrm{C}$ coupling in electrochemical $\mathrm{CO}_{2}$ reduction. Nat. Catal. 1, 111-119 (2018).

16. Luc, W. et al. Two-dimensional copper nanosheets for electrochemical reduction of carbon monoxide to acetate. Nat. Catal. 2, 423-430 (2019).

17. Han, N. et al. Ultrathin bismuth nanosheets from in situ topotactic transformation for selective electrocatalytic $\mathrm{CO}_{2}$ reduction to formate. Nat. Commun. 9, 1320 (2018).

18. Lee, C. H. \& Kanan, M. W. Controlling $\mathrm{H}^{+}$vs $\mathrm{CO}_{2}$ reduction selectivity on $\mathrm{Pb}$ electrodes. ACS Catal. 5, 465-469 (2014)

19. Dutta, A. et al. Probing the chemical state of tin oxide NP catalysts during $\mathrm{CO}_{2}$ electroreduction: a complementary operando approach. Nano Energy 53, 828-840 (2018).

20. Raciti, D., Livi, K. J. \& Wang, C. Highly dense $\mathrm{Cu}$ nanowires for lowoverpotential $\mathrm{CO}_{2}$ reduction. Nano Lett. 15, 6829-6835 (2015).

21. Liang, Y., Zhou, W., Shi, Y., Liu, C. \& Zhang, B. Unveiling in situ evolved $\mathrm{In} / \mathrm{In}_{2} \mathrm{O}_{3-\mathrm{x}}$ heterostructure as the active phase of $\operatorname{In}_{2} \mathrm{O}_{3}$ toward efficient electroreduction of $\mathrm{CO}_{2}$ to formate. Sci. Bull. https://doi.org/10.1016/j. scib.2020.1004.1022 (2020).

22. Chen, Y., Li, C. W. \& Kanan, M. W. Aqueous $\mathrm{CO}_{2}$ reduction at very low overpotential on oxide-derived Au nanoparticles. J. Am. Chem. Soc. 134, 19969-19972 (2012).

23. Kumar, B. et al. Reduced $\mathrm{SnO}_{2}$ porous nanowires with a high density of grain boundaries as catalysts for efficient electrochemical $\mathrm{CO}_{2}$-into $\mathrm{HCOOH}$ conversion. Angew. Chem. Int. Ed. 56, 3645-3649 (2017).

24. Deng, W. et al. Crucial role of surface hydroxyls on the activity and stability in electrochemical $\mathrm{CO}_{2}$ reduction. J. Am. Chem. Soc. 141, 2911-2915 (2019).

25. $\mathrm{Hu}, \mathrm{C}$. et al. In situ electrochemical production of ultrathin nickel nanosheets for hydrogen evolution electrocatalysis. Chem 3, 122-133 (2017).

26. Weng, Z. et al. Active sites of copper-complex catalytic materials for electrochemical carbon dioxide reduction. Nat. Commun. 9, 415 (2018).

27. Hartley, J. M. et al. EXAFS study into the speciation of metal salts dissolved in ionic liquids and deep eutectic solvents. Inorg. Chem. 53, 6280-6288 (2014).

28. Ejima, H. et al. One-step assembly of coordination complexes for versatile film and particle engineering. Science 341, 154-157 (2013).

29. Innocent, B. et al. Electro-reduction of carbon dioxide to formate on lead electrode in aqueous medium. J. Appl. Electrochem. 39, 227-232 (2008).

30. He, Z. et al. Electrochemically created roughened lead plate for electrochemical reduction of aqueous $\mathrm{CO}_{2}$. Catal. Commun. 72, 38-42 (2015).

31. García, J., Jiménez, C., Martínez, F., Camarillo, R. \& Rincón, J. Electrochemical reduction of $\mathrm{CO}_{2}$ using $\mathrm{Pb}$ catalysts synthesized in supercritical medium. J. Catal. 367, 72-80 (2018).
32. Jana, A., Ba, Q. \& Kim, K. S. Compositional and dimensional control of 2D and quasi-2D lead halide perovskites in water. Adv. Funct. Mater. 29, 1900966 (2019).

33. Yu, X., Diao, Q., Zhang, X., Lee, Y.-I. \& Liu, H.-G. In situ generated $\mathrm{Pb}$ nanoclusters on basic lead carbonate ultrathin nanoplates as an effective heterogeneous catalyst. CrystEngComm 19, 2860-2869 (2017).

34. Shi, Y., Yu, Y., Liang, Y., Du, Y. \& Zhang, B. In situ electrochemical conversion of an ultrathin tannin nickel iron complex film as an efficient oxygen evolution reaction electrocatalyst. Angew. Chem. Int. Ed. 58, 3769-3773 (2019)

35. Frantz, J. D. Raman spectra of potassium carbonate and bicarbonate aqueous fluids at elevated temperatures and pressures: Comparison with theoretical simulations. Chem. Geol. 152, 211-225 (1998).

36. Brooker, M. H., Sunder, S., Taylor, P. \& Lopata, V. J. Infrared and Raman spectra and X-ray diffraction studies of solid lead(II) carbonates. Can. J. Chem. 61, 494-502 (1983).

37. Jiang, K., Wang, J.-Y., Zhao, T.-T. \& Cai, W.-B. Formic acid oxidation at palladium electrode in acidic media containing chloride anions: an in situ ATR-SEIRAS investigation. J. Electroanal. Chem. 800, 77-81 (2017).

38. Cuesta, A., Cabello, G., Osawa, M. \& Gutiérrez, C. Mechanism of the electrocatalytic oxidation of formic acid on metals. ACS Catal. 2, 728-738 (2012)

39. Gao, D., Zhang, X. \& Gao, W. Formation of bundle-shaped beta-NaYF 4 upconversion microtubes via Ostwald ripening. ACS Appl. Mater. Inter. 5, 9732-9739 (2013)

40. Li, R., Luo, Z. \& Papadimitrakopoulos, F. Redox-assisted asymmetric Ostwald ripening of CdSe dots to rods. J. Am. Chem. Soc. 128, 6280-6281 (2006).

41. Martinetto, P., Anne, M., Dooryhée, E., Walter, P. \& Tsoucaris, G. Synthetic hydrocerussite, $2 \mathrm{PbCO}_{3} \cdot \mathrm{Pb}(\mathrm{OH})_{2}$, by X-ray powder diffraction. Acta Crystallogr. C 58, i82 (2002).

42. Vasquez, F. A., Heaviside, R., Tang, Z. \& Taylor, J. S. Effect of free chlorine and chloramines on lead release in a distribution system. J. Am. Water Works Ass. 98, 144-154 (2006).

43. Ravel, B. \& Newville, M. ATHENA, ARTEMIS, HEPHAESTUS: data analysis for X-ray absorption spectroscopy using IFEFFIT. J. Synchrotron Radiat. 12 537-541 (2005).

44. Kresse, G. \& Furthmüller, J. Efficiency of ab-initio total energy calculations for metals and semiconductors using a plane-wave basis set. Comp. Mater. Sci. 6 , 15-50 (1996)

45. Kresse, G. \& Furthmüller, J. Efficient iterative schemes for ab initio total-energy calculations using a plane-wave basis set. Phys. Rev. B 54, 11169-11186 (1996).

46. Zhang, Y. \& Yang, W. Comment on "Generalized gradient approximation made simple”. Phys. Rev. Lett. 80, 890 (1997).

47. Nørskov, J. K. et al. Origin of the overpotential for oxygen reduction at a fuelcell cathode. J. Phys. Chem. B 108, 17886-17892 (2004).

48. Han, M. et al. Toward computational design of catalysts for $\mathrm{CO}_{2}$ selective reduction via reaction phase diagram analysis. Adv. Theory Simul. 1800200 (2019).

49. Nie, X., Esopi, M. R., Janik, M. J. \& Asthagiri, A. Selectivity of $\mathrm{CO}_{2}$ reduction on copper electrodes: the role of the kinetics of elementary steps. Angew. Chem. Int. Ed. 52, 2459-2462 (2013).

50. Akhade, S. A., Bernstein, N. J., Esopi, M. R., Regula, M. J. \& Janik, M. J. A simple method to approximate electrode potential-dependent activation energies using density functional theory. Catal. Today 288, 63-73 (2017).

51. Katayama, Y. et al. An in situ surface-enhanced infrared absorption spectroscopy study of electrochemical $\mathrm{CO}_{2}$ reduction: selectivity dependence on surface C-bound and O-bound reaction intermediates. J. Phys. Chem. C 123, 5951-5963 (2018).

\section{Acknowledgements}

We acknowledge the National Natural Science Foundation of China (Nos. 21871206 21901180, 21422104, 91845103, and 21802124), the Natural Science Foundation of Tianjin City (No. 17JCJQJC44700), China Postdoctoral Science Foundation (No. 2019TQ0226), the Strategic Priority Research Program of Chinese Academy of Sciences (No. XDB36030200), and Liaoning Revitalization Talents Program (XLYC1907099) for financial support. We acknowledge Dr. Lirong Zheng and the 1W1B beamline of the Beijing Synchrotron Radiation Facility for supporting this project.

\section{Author contributions}

B.Z. conceived and directed the project. B.Z. and Y.S. designed the experiments. Y.S and Y.J. carried out the experiments. J.L. and J.X. performed and analyzed the DFT calculations. Y.L. carried out the in situ Raman spectroscopy. Y.S. and Y.L. conducted the in situ ATR-FTIR spectroscopy. Y.S. and J.L. wrote the paper. Y.Y., J.X., and B.Z. revised the paper. All authors discussed the results and commented on the paper.

\section{Competing interests}

The authors declare no competing interests. 


\section{Additional information}

Supplementary information is available for this paper at https://doi.org/10.1038/s41467020-17120-9.

Correspondence and requests for materials should be addressed to J.X. or B.Z.

Peer review information Nature Communications thanks Su-Il In, Fabiola Martínez, and other, anonymous, reviewer(s) for their contributions to the peer review of this work. Peer review reports are available.

Reprints and permission information is available at http://www.nature.com/reprints

Publisher's note Springer Nature remains neutral with regard to jurisdictional claims in published maps and institutional affiliations. (c) (i) Open Access This article is licensed under a Creative Commons Attribution 4.0 International License, which permits use, sharing, adaptation, distribution and reproduction in any medium or format, as long as you give appropriate credit to the original author(s) and the source, provide a link to the Creative Commons license, and indicate if changes were made. The images or other third party material in this article are included in the article's Creative Commons license, unless indicated otherwise in a credit line to the material. If material is not included in the article's Creative Commons license and your intended use is not permitted by statutory regulation or exceeds the permitted use, you will need to obtain permission directly from the copyright holder. To view a copy of this license, visit http://creativecommons.org/ licenses/by/4.0/.

(C) The Author(s) 2020 